\title{
Methodology for the Study of the Quality of CFRP Dry Drilling Based on Macrogeometrical and Dimensional Deviations
}

\author{
J. Salguero*, S. R. Fernandez-Vidal, P. Mayuet, J. M. Vazquez-Martinez, M. Alvarez, M. Marcos \\ Mechanical Engineering and Industrial Design Department, University of Cadiz, Cadiz, Spain \\ Email: *jorge.salguero@uca.es
}

How to cite this paper: Salguero, J., Fernandez-Vidal, S.R., Mayuet, P., Vazquez-Martinez, J.M., Alvarez, M. and Marcos, M. (2016) Methodology for the Study of the Quality of CFRP Dry Drilling Based on Macrogeometrical and Dimensional Deviations. World Journal of Engineering and Techno$\log$, , 4, 200-205.

http://dx.doi.org/10.4236/wjet.2016.43D024

Received: September 24, 2016

Accepted: October 13, 2016

Published: October 20, 2016

\begin{abstract}
Commonly, Carbon Fiber Reinforced Plastics (CFRP) aerospace elements need to be machined (drilling) for subsequent assembly operations, mainly riveting, taking a critical importance the quality requirements of the holes. Some of the adjustment defects that can be produced during the dry drilling of CFRP are related to macrogeometrical (diameter, D, and cylindricity, DC) deviations. This paper reports on the results of a study of the influence of the cutting parameters $V$ (cutting speed) and $f$ (feedrate) on the D and DC deviations in the dry drilling of CFRP. A particular procedure based on plastic hole replicas has been performed. Diameters deviations were acceptable in all the cases studied. Because of this, DC is the controlling factor for accepting the drilled holes. In the studied range, lowest cutting speeds and highest feedrates have allowed obtaining the minimum cylindricity deviation.
\end{abstract}

\section{Keywords}

Dry Drilling, CFRP, Macrogeometrical Deviations, Cylindricity, Diameter

\section{Introduction}

Control of the aircraft's weight is one of the main mandatory contractual points for the aerospace companies, being reviewed in reference to two values; Not to Exceed Weight (NTEW) and Target Weight (TW). If the NTEW is exceeded then $\$ 1000 / \mathrm{kg}$ per aircraft must be paid to the final client, while if the aircraft manufacturers manage to go below the TW, final clients pay them a bonus of $\$ 500 / \mathrm{kg}$ in each aircraft [1]. In this search for reducing weight, and so emissions and fuel efficiency, composite materials have played a key role. Currently there are three main types in use: carbon, glass and aramid fiber reinforced epoxy, classified into the so-named Fiber Reinforced Plastics (FRP) [2] [3]. 
Nevertheless carbon fiber is the reinforcement material of choice for "advanced" composites, because it exhibits excellent fatigue resistance which do not suffer from stress rupture compared with glass or aramid fibers. This kind of advanced material is commonly called as Carbon Fiber Reinforced Plastic or Polymer (CFRP) [2].

Structural parts made of CFRP have frequently to be drilled and riveted afterwards during the assembly operations. So, machining processes have to guarantee the tight dimensional and geometric tolerances specified in the quality requirements [4] [5]. Usually, the damages of drilling FRPs are classified into four categories: delamination at entry, geometric defects, temperature-related damages and delamination at exit [6]. Among the geometric defects, control of cylindricity errors, together with the diameter deviations, are key factors in major aerospace manufacturers, due to these are directly related to the correct assembly and proper functioning of the rivets [7] [8].

When CFRP is drilling, the tool geometry related damages are associated to the angle between fibers orientation and the cutting edge [9]. This occurs due to the fact that before shearing takes place, the fibers are subject to alternate torsion and compression, resulting on an elliptical hole, in which the smaller axis of the ellipse is in the same direction of the fibers and is inferior to the drill diameter [10]. On the other hand, cutting tool wear in the dry drilling of CFRP is mainly based on abrasion mechanism, in which the cutting tool gradually lose its initial geometry, and so affecting to all the features involved in the geometrical and dimensional tolerances [11].

Majority of the researches in the domain of geometrical tolerances are done for various types of errors associated in achieving these tolerances. The error compensation strategies are also developed, and various innovative models and techniques were developed to measure various geometrical tolerances. However, the work related to cutting parameters, its investigation, its contribution and its selection to optimize the geometrical errors need some amount of focus. In this paper, a preliminary study of the influence of the cutting parameters on the holes quality has been developed. Dimensional deviations (taking as reference the difference between measured and nominal hole diameters) and cylindricity deviations (as a macrogeometrical deviation parameter that combines the effect of roundness, straightness and parallelism deviations) have taken as a measurement of the holes macro-quality in the dry drilling of CFRP sheets.

\section{Experimental Methodology}

The experimental procedure contains two sequential stages:

1) Design and development of drilling test, including technological parameters selection, clamping device design and drilling cycles programming.

2) OFF-LINE evaluation of holes quality on the basis of metrological considerations. In this case, according to the objectives of the paper, both dimensional deviationsbased on the difference between measured (D) and nominal (D0) diameters-and cylindricity deviations-by combining roundness, straightness and parallelism deviations-have been selected as hole quality variables. 


\subsection{Dry Drilling Tests}

$210 \times 210 \times 4.5(\mathrm{~mm})$ sheets of CFRP (34\% epoxy) with (0/90/45/-45/45/-45) layer orientation, have been used as test material for being drilled. Uncoated SANDVIK VUS85CS0377 WC-Co drills have been used as cutting tools, Table 1. Dry drilling tests were conducted in a High Speed Machining Center (HSMC) Kondia Five 400, equipped with a Heidenhain iTNC-530 CNC. A special tooling equipment were applied for clamping the samples, Figure 1. The dry drilling tests were performed combining two extreme values of cutting speed $(\mathrm{V})$ and feedrate $(\mathrm{f})$ selected from previous work developed on this kind of materials. A cutting speed of $85 \mathrm{~m} / \mathrm{min}$ and feedrate of 250 $\mathrm{mm} / \mathrm{min}$ were selected from the cutting-tool manufacturer. Also, a higher cutting speed of $145 \mathrm{~m} / \mathrm{min}$ and a higher feedrate of $400 \mathrm{~mm} / \mathrm{min}$ were selected in order to obtain a widest range of results in a high productivity rate, although in a more aggressive cutting conditions. So, a total of 4 tests have been conducted, taking into account all the possible combinations V-f. As this is a preliminary study, only a set of 25 drills has been carried out in each one of the dry drilling tests, using new cutting tools for each test.

\subsection{Metrological Evaluation}

Hole diameters were evaluated by using a millesimal Mitutoyo Digimatic 3-contacts bore micrometer, measuring at 3 levels equispaced $120^{\circ}$. Experimental diameter value was taken as the average of the three recorded values. Cylindricity deviations were evaluated using a Mahr Formtester MMQ 44, as the average deviation of 6 roundness measures along the body of the hole. For this purpose, and due to the geometry of the drilling samples, a Plastiform RGX 80 resin was use to obtain a replica of each hole, Figure 2. This procedure has been validate by aerospace companies geographically close to our labs.
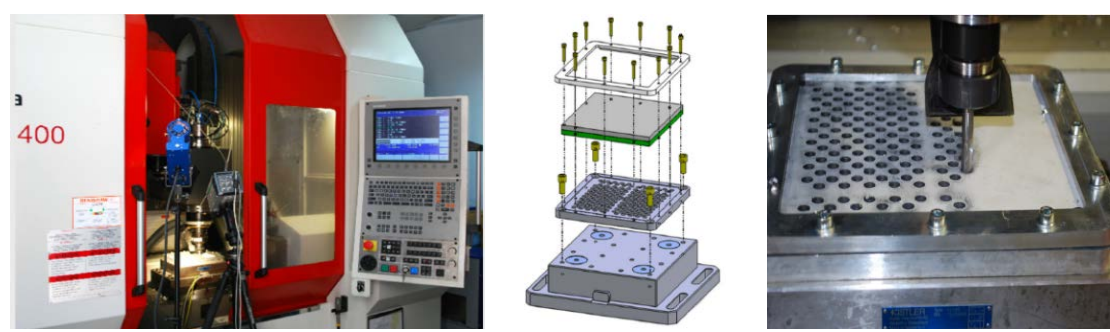

Figure 1. Kondia Five 400 (left). Detail of tooling (center). CFRP drilling process (right).

Table 1. Cutting toolgeometrical parameters.

\begin{tabular}{|c|c|c|c|c|c|c|c|c|}
\hline & & $\frac{\downarrow}{\mathrm{DCON}}$ & $\left.\right|_{O A}$ & LU & 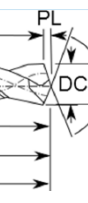 & 38 & & \\
\hline $\begin{array}{c}\text { DC } \\
(\mathrm{mm})\end{array}$ & $\begin{array}{c}\mathrm{LU} \\
(\mathrm{mm})\end{array}$ & $\begin{array}{c}\text { DCON } \\
(\mathrm{mm})\end{array}$ & $\begin{array}{l}\text { SIG } \\
\left({ }^{\circ}\right)\end{array}$ & $\begin{array}{c}\mathrm{PL} \\
(\mathrm{mm})\end{array}$ & $\begin{array}{l}\text { OAL } \\
(\mathrm{mm})\end{array}$ & $\begin{array}{c}\mathrm{LF} \\
(\mathrm{mm})\end{array}$ & $\begin{array}{c}\mathrm{LCF} \\
(\mathrm{mm})\end{array}$ & $\begin{array}{c}\text { Helix } \\
\left({ }^{\circ}\right)\end{array}$ \\
\hline 7.921 & 25.00 & 8.00 & $118.00 / 140.00$ & 1.20 & 80.00 & 78.80 & 30.00 & 30.00 \\
\hline
\end{tabular}




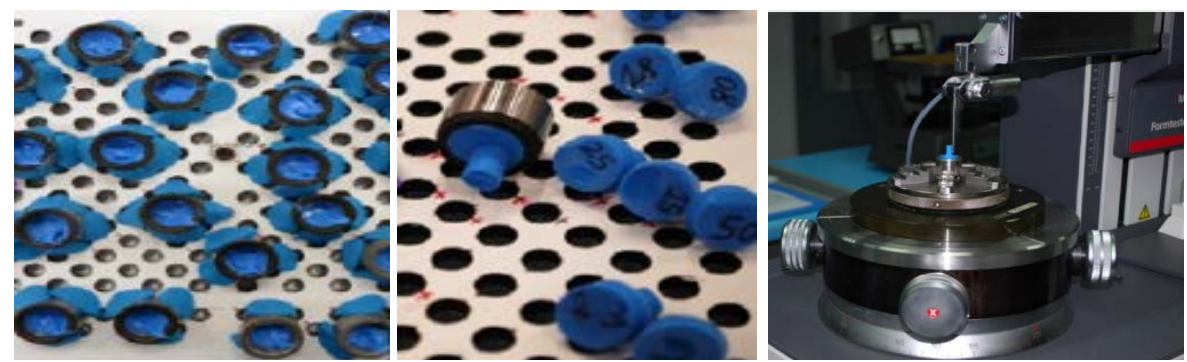

Figure 2. Resin curing process inside the holes (left). Samples for cylincricity measurement (center). Mahr Formtester MMQ 44 (right).

\section{Results and Discussion}

Figure 3 plots the evolution of the measured diameters as a function of the number of holes, for each cutting speed used. Two reference horizontal lines have been included. Lower line defines the nominal diameter based on the average diameter of cutting tool. Upper line defines the maximum admitted value (tolerance) in the recent Airbus A350 XWB program. This defines a tolerance range of $64 \mu \mathrm{m}$.

As it can be observed, all the values can be accepted because they are placed into the tolerance range. All the $\mathrm{D}$ values are higher than $\mathrm{D}_{0}$. This is associated to the plastic compression of CFRP. The influence of the cutting temperature does not seem be affected with the machining time because it cannot be detected appreciable changes with the number of holes $(\mathrm{N})$. However, cutting speed $(\mathrm{V})$ provokes a soft increase of the values of $\mathrm{D}$ that can be associated to the thermal expansion of the carbon fibers, which like others temperature-related damages [6], has a strong dependence on the cutting speed [8]. On the other hand, in a very fine analysis, a very soft decreasing of the $D(N)$ branches value of the diameter with the number of holes can be detected. Although the number of drilling is only 25 , it can be related to the tool wear. In effect, as it can be observed in the SEM images of drilling tools included in Figure 4, slight signs of abrasive wear can be distinguished. This kind of wear can diminished the average diameter of the tool and it can provoke a negative evolution of $\mathrm{D}(\mathrm{N})$ values.

Figure 5 plots the evolution of cylindricity deviation, DC, as a function of the number of drills $(\mathrm{N})$ for the different cutting parameters applied.

In the drilling of CFRP and/or light alloy plates with thicknesses less than $14 \mathrm{~mm}$, aeronautical requirements about cylindricity deviations requires values lower than 150 $\mu \mathrm{m}$. All the values included are placed into this range, but potential growths were observed in all cases, associated to a continuous abrasive wear in the cutting tool edges. Also it is noticeable that excellent results have been found when higher feedrate is used at lower cutting speed, while low feedrate shows higher dispersion for both cutting speeds. This fact cannot be attributed solely to tool wear, but may be due to temperature-related damages in form of thermal gradients produced during the cutting process [6], which can degrade and even evaporate part of the epoxy resin. No temperature evolution effects can be distinguished. So, using extreme values, long-term tests are currently under design and development. 


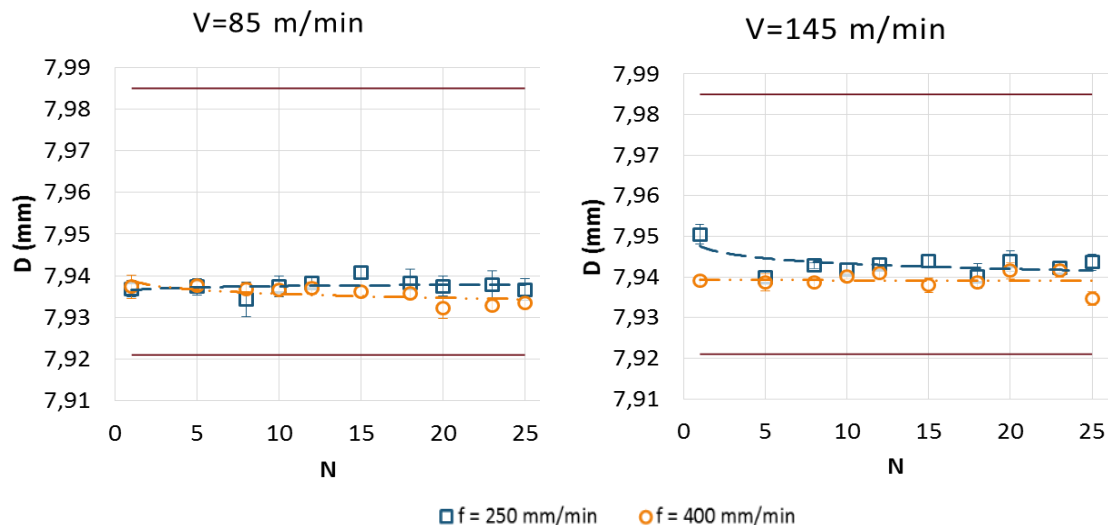

Figure 3. Diameter (D) evolution as a function of the number of drills (N).
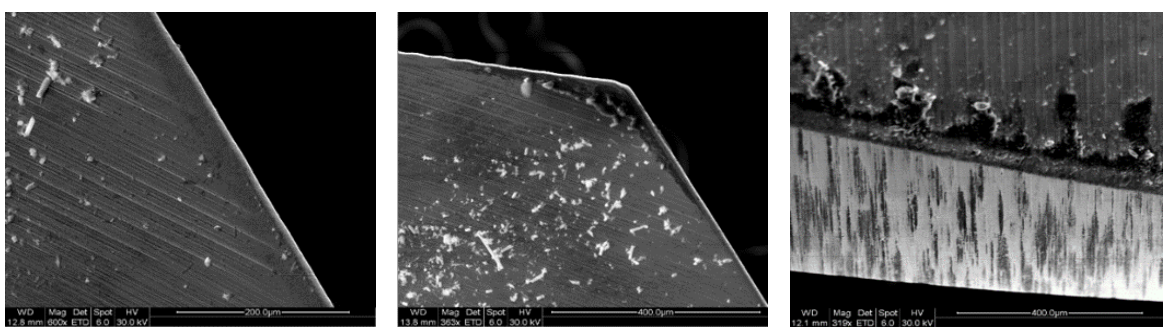

Figure 4. SEM images of the cutting tool after 25 holes $(\mathrm{V}=85 \mathrm{~m} / \mathrm{min}, \mathrm{f}=250 \mathrm{~mm} / \mathrm{min})$. Rake face (left). Margin (center). Clearance face (right).

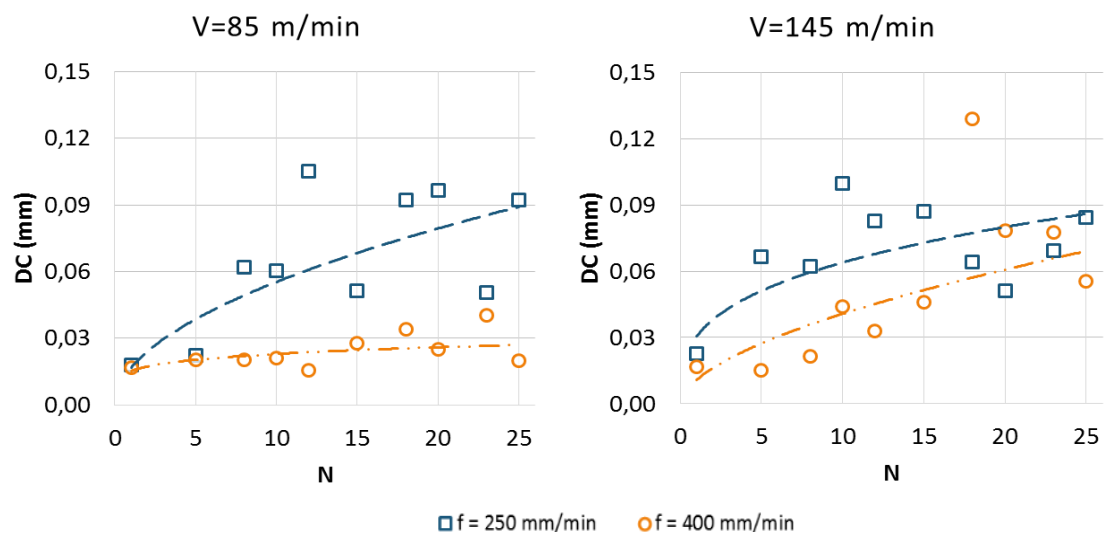

Figure 5. Cylindricity deviation (DC) evolution as a function of the number of drills (N).

\section{Conclusion}

Dry drilling of CFRP is a complex operation, due to the amount of factors that can affect the final quality of the holes. Among them, diameter tolerances and cylindrical deviations are key parameters to ensure the correct functioning of the rivets. When CFRP is dry-drilled under the tested conditions, tight diameter tolerances $(20 \mu \mathrm{m})$ are achieved. However, the plastic effects cause an increase of about 15 - $20 \mu \mathrm{m}$. Good results in cylindricity deviations were found when the higher feedrate and the lower cutting speed were used. It must be noticed that all the values obtained for dimensional and macrogeometrical deviations have been found into the tolerance range. 


\section{Acknowledgements}

This work has been funded by the Spanish Government (Project DPI2015-71448-R), from the European Union (FEDER/FSE) and from the Andalusian Government (Project DIANNA-INTERCONNECTA). Authors want to thank to AIRBUS D\&S the collaboration in the research associated to this paper.

\section{References}

[1] Sánchez, A. (2016) Weight Control on A350 XWB. Alestis Aerospace Newsletter, 4, 20. http://www.alestis.aero/wp-content/uploads/2016/05/Flying-N4-WEB.pdf

[2] Rosato, D.V. and Rosato, D.V. (2004) Reinforced Plastic Handbook. 3rd Edition, Elsevier, Oxford.

[3] Bunsell, A.R. and Renard, J. (2005) Fundamentals of Fiber Reinforced Materials. Institute of Physics Publishing, London. http://dx.doi.org/10.1201/9781420056969

[4] Mayuet, P., Gallo, A., Portal, A., Arroyo, P., Alvarez, M. and Marcos, M. (2013) Damaged Area Based Study of the Break-IN and Break-OUT Defects in the Dry Drilling of Carbon Fibre Reinforced Plastics (CFRP). Procedia Engineering, 63, 743-751. http://dx.doi.org/10.1016/j.proeng.2013.08.249

[5] Yan, Q.B. and Chen, W.L. (2015) Automatic Modification of Local Drilling Holes via Double Pre-Assembly Holes. World Journal of Engineering and Technology, 3, 191-196. http://dx.doi.org/10.4236/wjet.2015.33C028

[6] Lachaud, F., Piquet, R., Collombet, F. and Surcin, L. (2001) Drilling of Composite Structures. Composite Structures, 52, 511-516. http://dx.doi.org/10.1016/S0263-8223(01)00040-X

[7] Drake, P.J. (1999) Dimensioning and Tolerancing Handbook. McGraw-Hill, New York.

[8] Sheth, S. and George, P.M. (2016) Experimental Investigation, Prediction and Optimization of Cylindricity and Perpendicularity during Drilling of WCB Material Using Grey Relational Analysis. Precision Engineering, 45, 33-43. http://dx.doi.org/10.1016/j.precisioneng.2016.01.002

[9] Abrao, A.M., Faria, E.E., Campos Rubio, J.C., Reis, P. and Davim, J.P. (2007) Drilling of Fiber Reinforced Plastics: A Review. Journal of Materials Processing Technology, 186, 1-7. http://dx.doi.org/10.1016/j.jmatprotec.2006.11.146

[10] Inoue, H., Aoyama, E., Hirogaki, T., Ogawa, K., Matushita, H., Kitahara, Y. and Katayama, T. (1997) Influence of Tool Wear on Internal Damage in Small Diameter Drilling in GFRP. Composite Structures, 39, 55-62. http://dx.doi.org/10.1016/S0263-8223(97)00068-8

[11] Alvarez-Alcon, M., Fernandez-Vidal, S.R., Clares, J.M., Mayuet, P.F., Batista, M. and Marcos, M. (2015) Microgeometrical Deviations Based Study of CFRP Drilled-Holes. Procedia Engineering, 132, 624-631. http://dx.doi.org/10.1016/j.proeng.2015.12.540 
Submit or recommend next manuscript to SCIRP and we will provide best service for you:

Accepting pre-submission inquiries through Email, Facebook, LinkedIn, Twitter, etc. A wide selection of journals (inclusive of 9 subjects, more than 200 journals)

Providing 24-hour high-quality service

User-friendly online submission system

Fair and swift peer-review system

Efficient typesetting and proofreading procedure

Display of the result of downloads and visits, as well as the number of cited articles

Maximum dissemination of your research work

Submit your manuscript at: http://papersubmission.scirp.org/

Orcontactwjet@scirp.org 